\title{
Two Cases of Seasonal Influenza Virus (H3N2) and Acute Respiratory Distress Syndrome
}

\section{Moo Hyun Kim, Bo Ra Yoon, Myung Jin Song, Ji Soo Choi, Sang Hoon Lee, Kyung Soo Chung}

Division of Pulmonary and Critical Care Medicine, Department of Internal Medicine, Institute of Chest Diseases, Severance Hospital, Yonsei University College of Medicine, Seoul, Korea

Compared with the 2009 pandemic influenza A (H1N1), the seasonal influenza A (H3N2) in 2011-2012 was self-limited and mild. However, some cases proceeded to acute respiratory distress syndrome (ARDS) due to underlying medical history. Here we report two cases with influenza A (H3N2) progressing to fatal ARDS. One case with several underlying medical conditions eventually died from multi-organ failure despite the application of extracorporeal membrane oxygenation. When patients are suspected to have influenza, it is imperative to investigate their medical histories and risk factors. If they have many co-morbidities or risk factors, clinicians should initiate aggressive management immediately regardless of the type of influenza infection.

Keywords: Respiratory distress syndrome, adult; H3N2; Seasonal influenza

\section{INTRODUCTION}

Influenza viruses are major causes of lower respiratory tract infections. Three influenza pandemics occurred during the 20th century. The 'Spanish flu' pandemic A (H1N1) emerged in 19181919 , and the second pandemic influenza A (H2N2) occurred in 1957-1958. In 1968, a new type A (H3N2) appeared and became epidemic [1]. Pandemic influenza virus A (H1N1) 2009 is associated with a higher risk of viral pneumonia than seasonal influenza virus A (H3N2). Most H3N2-seasonal influenza A (2011-2012) patients experienced mild, self-limited influenza-like illness. However, some patients were at increased risk for influenza complications such as severe pneumonia and acute respiratory distress syndrome (ARDS) due to old age or underlying medical history [2]. Recently, several reports have noted that the seasonal influenza virus A (H3N2) caused severe respiratory infection and induced diffuse alveolar damage in some patients during the influenza epidemic season 2011-2012 [3]. Here, we report the first two cases of ARDS caused by seasonal influenza virus A (H3N2) in Korea.

\section{CASE REPORTS}

\section{Case report 1}

A 50-year-old man who had experienced two days of cough, sputum, fever, and myalgia visited Severance Hospital emergency room via the local medical center. The patient had been diagnosed with rheumatic mitral stenosis and aortic regurgitation in 2010, and underwent mitral valve and aortic valve replacement. His other past history included diabetes mellitus, Behcet's disease, and atrial fibrillation. He did not receive the influenza vaccination on the day of admission. Chest computed tomography (CT) revealed both lower and right upper lobe pneumonic consolidation (Fig. $1 \mathrm{~A}, \mathrm{C}$ ). Initial vital signs included high fever spiking (blood pressure, 145/79 mm Hg; heart rate, 89 rate/min; body temperature, $38.4^{\circ} \mathrm{C}$ ) and laboratory studies revealed elevated inflammatory markers (C-reactive protein, $222.6 \mathrm{mg} / \mathrm{L}$ [normal range, 0 to $8 \mathrm{mg}$ / L]). He was admitted for treatment of health care associated pneumonia and we started antibiotics and oseltamivir empirically (75 mg twice per day for 5 days). However, the patient's clinical condition continued to worsen, so he was transferred to the intensive
Correspondence to: Kyung Soo Chung

Division of Pulmonary and Critical Care Medicine, Department of Internal Medicine, Yonsei University Health System, Yonsei University College of Medicine, 50-1 Yonsei-ro, Seodaemun-gu, Seoul 03722, Korea

Tel: +82-2-2227-4203, Fax: +82-2-393-6884, E-mail: CHUNGKS@yuhs.ac

Received: May 1, 2016 / Accepted after revision: Sep. 6, 2016
(C) 2016 Soonchunhyang Medical Research Institute This is an Open Access article distributed under the terms of the Creative Commons Attribution Non-Commercial License (http://creativecommons.org/licenses/by-nc/4.0/). 

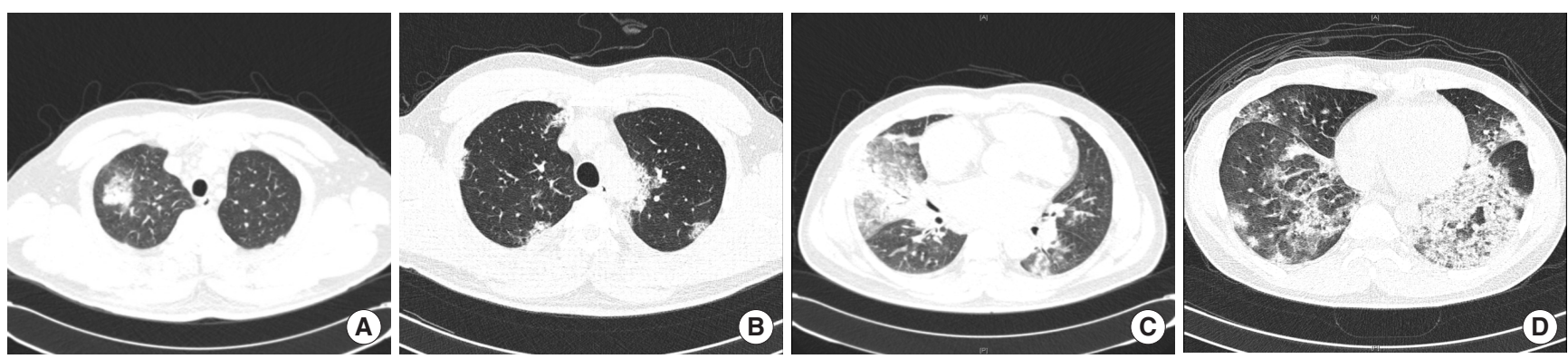

Fig. 1. Chest CT of chest. (A, C) A chest CT of case 1 evaluated upon admission show multifocal consolidation in both lungs and lobar consolidation in right middle lungs. (B, D) A chest CT of case 2 taken upon admission reveal lobular, peribronchial and subpleural consolidation in both lungs. CT, computed tomography.
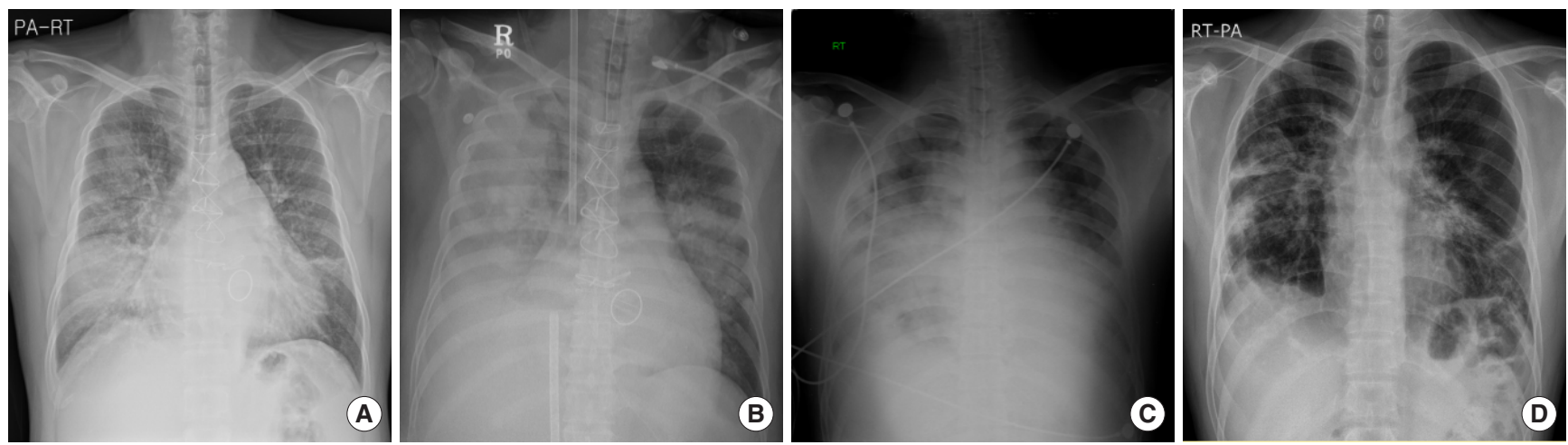

Fig. 2. Chest radiographs of two cases at hospital day 1 and 7. (A, C) Chest radiograph of case 1. A chest X-ray taken upon ICU admission show consolidation of right middle lobe. Despite ICU care, the patient's condition get worsened. Chest X-ray on ICU day 7 show progression of consolidation. (B, D) Chest radiograph of case 2. A chest $\mathrm{X}$-ray taken on ICU admission reveal bilateral infiltrates. Chest X-ray taken on ICU day 7 reveal marked resolution of consolidation. ICU, intensive care unit. PA, posterior-anterior; $\mathrm{RT}$, right.

care unit (ICU). With clinical and radiological signs of ARDS progression, he was intubated and started mechanical ventilator care on hospital day 2. Ventilator settings followed standard lung-protective strategies (tidal volume $6 \mathrm{~mL} / \mathrm{kg}$ of predicted ideal body weight with plateau pressure lower than maximum $30 \mathrm{~cm} \mathrm{H}_{2} \mathrm{O}$ ) [4]. Echocardiography showed a well-functioning prosthetic valve and his ejection fraction (EF) was $69 \%$ within normal range. For influenza virus identification, we collected sputum by fiber-optic bronchoscopy and analyzed the sample using Advansure TM RV real-time reverse transcription-polymerase chain reaction (PCR; LG Life Science, Daejeon, Korea). PCR assays of nasal swab and bronchoalveolar lavage samples were positive for viral genomes of the $\mathrm{H} 3 \mathrm{~N} 2$ virus. Despite high fraction of inspired oxygen $\left(\mathrm{FiO}_{2}\right)$ supply and rescue therapy including prone positioning and recruitment maneuvers, the patient's hypoxia was not resolved, and therefore three days after admission extracorporeal membrane oxygenation (ECMO) treatment was started using the Capiox emergency bypass system (emergency bypass system; Terumo Inc., Tokyo, Japan). Despite the application of ECMO, the patient showed septic exacerbation with fevers of up to $39^{\circ} \mathrm{C}$, increased laboratory markers of inflammation (C-reactive protein, $352 \mathrm{mg}$ / $\mathrm{L}$ [normal range, 0 to $8 \mathrm{mg} / \mathrm{L}$ ]; procalcitonin, $80.44 \mathrm{ng} / \mathrm{mL}$ [normal range, 0 to $0.5 \mathrm{ng} / \mathrm{mL}]$ ), which revealed the presence of hepatitis and pancytopenia (aspartate aminotransferase, 1,222 IU/L [normal range, 13 to $34 \mathrm{IU} / \mathrm{L}$; ; alanine aminotransferase, $466 \mathrm{IU} / \mathrm{L}$ [normal range, 5 to $46 \mathrm{IU} / \mathrm{L}$; white blood cell [WBC], $1.97 \times 10^{3} / \mathrm{uL}$ [normal range, 4.0 to $10.810^{3} / \mu \mathrm{L}$ ]; hemoglobin, $9.7 \mathrm{~g} / \mathrm{dL}$ [normal range, 13.0 to $17.4 \mathrm{~g} / \mathrm{dL}$ ]; platelet count, $56 \times 10^{3} / \mu \mathrm{L}$ [normal range, 150 to $\left.\left.40010^{3} / \mu \mathrm{L}\right]\right)$. Chest X-ray showed aggravated pulmonary infiltration and the EF was decreased by $31 \%$, so we exchanged veno-venous ECMO for veno-arterial ECMO due to low oxygenation (Fig. 2A, C). Treatment with specific antiviral drugs was unsuccessful and the patient developed multiple organ failure. After 3 days of ECMO, the patient died.

\section{Case report 2}

A 37-year-old male patient had a cough, fever as high as $39.5^{\circ} \mathrm{C}$, and dyspnea that did not improve despite medication for a period 
Kim MH, et al. • Seasonal Influenza, H3N2, Acute Respiratory Distress Syndrome

of 10 days. He was admitted to a local hospital for 4 days. He had no co-morbidities or any other relevant past history. He had not been vaccinated against influenza that year. His clinical condition had been worsening, so the patient was referred to the emergency department. Initial vital signs were stable (blood pressure, $10^{3} / 62$ $\mathrm{mm} \mathrm{Hg}$; heart rate, $96 \mathrm{rate} / \mathrm{min}$; body temperature, $36.9^{\circ} \mathrm{C}$ ) and laboratory study revealed hypoxia (arterial oxygen partial pressure $\left[\mathrm{PaO}_{2}\right.$ ], $56.9 \mathrm{~mm} \mathrm{Hg}$ [normal range, 83 to $108 \mathrm{~mm} \mathrm{Hg}$ ]), bicytopenia (WBC, $1.70 \times 10^{3} / \mu \mathrm{L}$ [normal range, 4.0 to $10.810^{3} / \mu \mathrm{L}$ ]; platelet count $53 \times 10^{3} / \mu \mathrm{L}$ [normal range, 150 to $40010^{3} / \mu \mathrm{L}$ ]), and inflammatory marker elevation (C-reactive protein, $198.1 \mathrm{mg} / \mathrm{L}$ [normal range, 0 to $8 \mathrm{mg} / \mathrm{L}$ ]). CT-scans performed after arriving at the emergency department showed extensive pneumonic consolidations, mostly in both lower lobes (Fig. 1B, D), so we started the patient on antibiotics and oseltamivir (75 $\mathrm{mg}$ twice per day for 5 days) empirically. Despite initial management, the patient's gas exchange continued to worsen $\left(\mathrm{PaO}_{2} / \mathrm{FIO}_{2}\right.$ at admission $=56.9$ $\mathrm{mm} \mathrm{Hg}$ ) and he showed respiratory fatigue. Therefore, we proceeded to intubation and started mechanical ventilation. Bronchoalveolar lavage PCR for influenza virus A (H3N2) was positive and other bacterial etiology was negative. Despite high positive end expiratory pressure levels the patient's severe hypoxemia persisted, and therefore the next day the patient was shifted to the prone position. After changing the patient to the prone position, oxygenation was improved. Two days after ICU admission the patient's clinical condition improved and pneumonic consolidation was resolved (Fig. 2B, D), so we started a weaning trial and extubated the patient 7 days after ICU admission. He was able to maintain spontaneous breathing and was discharged after 18 days of admission in the ICU.

\section{DISCUSSION}

This is the first case report of seasonal influenza A (H3N2) leading to severe ARDS in Korea. The pathogenesis of ARDS is known to include the influenza virus, starting with the breakdown of the epithelial-endothelial barrier, fluid leakage into the alveoli, and leading eventually to respiratory failure [5]. Many patients experienced progression to severe lower respiratory infections during the 2009 influenza A (H1N1) pandemic period, and required treatment with rescue therapy, like prone positioning, recruitment maneuvers, and ECMO due to ARDS. Although most cases of seasonal influenza (H3N2) usually follow a benign course and are self-limited, some cases of influenza-H3N2 proceed to severe ARDS. There were two cases of seasonal influenza (H3N2) developing to ARDS in 2011-2012 reported in Italy (Table 1) [3]. This previous study found that patients with several relevant past medical history factors tended to have poor prognosis. In 2014-2015, an additional report described two cases of severe lower respiratory infection due to subtype H3N2 and progression to ARDS (Table 2). In these cases, the H3N2-influenza virus may also have influenced the endothelial-epithelial barrier, and generated alveolar

Table 1. Cases of influenza-H3N2 induced acute respiratory distress syndrome

\begin{tabular}{|c|c|c|c|c|c|c|c|}
\hline Patient & Age (yr) & Sex & Initial clinical manifestation & Pathogen & Underlying disease & Treatment & Outcome \\
\hline Case 1 & 50 & Male & Cough, sputum, fever, myalgia & Influenza A-H3N2 & $\begin{array}{l}\text { Valvular heart disease, behcet } \\
\text { disease, diabetes mellitus }\end{array}$ & $\begin{array}{l}\text { Oseltamivir } 150 \text { mg twice per } \\
\text { day for } 5 \text { days }\end{array}$ & Death \\
\hline Case 2 & 37 & Male & Fever, cough, dyspnea & Influenza A-H3N2 & None & $\begin{array}{l}\text { Oseltamivir } 150 \text { mg twice per } \\
\text { day for } 5 \text { days }\end{array}$ & Survival \\
\hline Case 3 (Italy) [3] & 66 & Male & Cough, sneezing & Influenz & $\begin{array}{l}\text { Rheumatoid arthritis, sjogren } \\
\text { syndrome }\end{array}$ & Oseltamivir $20 \mathrm{mg}$ twice per day & Death \\
\hline Case 4 (Italy) [3] & 76 & Male & Fever, cough, dyspnea & Influenza A-H3N2 & Diabetes mellitus, arteriopathy & Oseltamivir $20 \mathrm{mg}$ twice per day & Survival \\
\hline
\end{tabular}

Table 2. Initial patient characteristics

\begin{tabular}{|c|c|c|c|c|c|c|c|c|c|c|}
\hline Patient & Sex/age (yr) & $\begin{array}{c}\text { Ejection } \\
\text { fraction (\%) at } \\
\text { ICU admission }\end{array}$ & $\begin{array}{l}\text { Charlson } \\
\text { co-morbidity } \\
\text { index }\end{array}$ & $\begin{array}{l}\text { Initial } \mathrm{PaO}_{2} / \mathrm{FiO}_{2}{ }^{\text {a) }} \\
\text { at ICU admission } \\
\qquad(\mathrm{mm} \mathrm{Hg})\end{array}$ & $\begin{array}{l}\text { Mechanical } \\
\text { ventilation } \\
\text { period (day) }\end{array}$ & $\begin{array}{l}\text { Extracorporeal } \\
\text { membrane } \\
\text { oxygenation } \\
\text { application }\end{array}$ & $\begin{array}{l}\text { Duration of } \\
\text { ICU stay (day) }\end{array}$ & $\begin{array}{l}\text { Sequential } \\
\text { organ failure } \\
\text { assessment } \\
\text { score }\end{array}$ & $\begin{array}{l}\text { Acute physiology } \\
\text { and chronic health } \\
\text { evaluation II score }\end{array}$ & Outcome \\
\hline Case 1 & Male/50 & 61 & 3 & 108 & 7 & Yes & 7 & 14 & 23 & Death \\
\hline Case 2 & Male/37 & 60 & 0 & 56.9 & 6 & None & 8 & 12 & 17 & Survival \\
\hline
\end{tabular}

ICU, intensive care unit.

${ }^{a}$ Arterial oxygen partial pressure/fraction of inspired oxygen. 

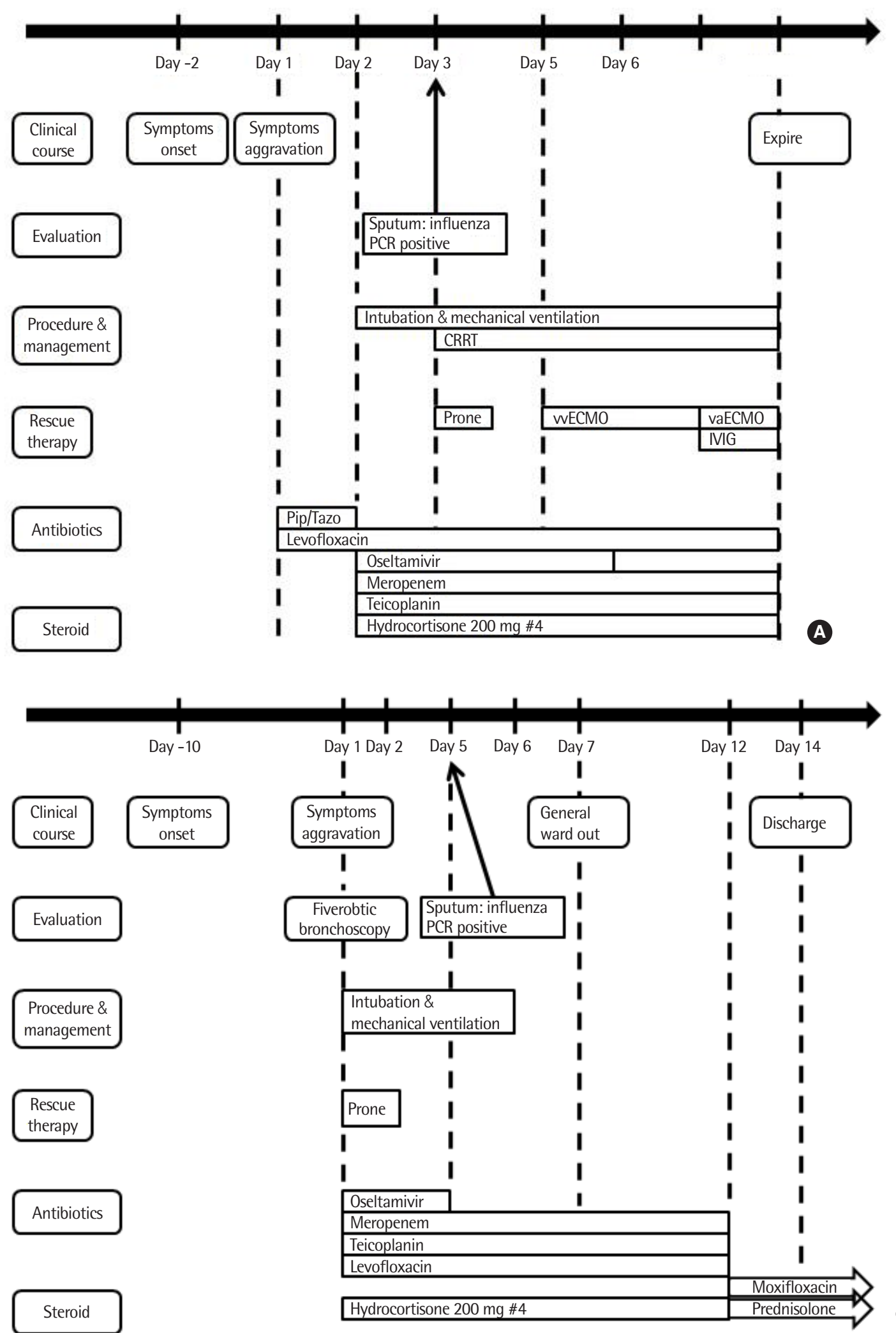

Fig. 3. Progress outlines of two cases. (A) Case 1. (B) Case 2. PCR, polymerase chain reaction; CRRT, continuous renal replacement therapy; Prone, prone position; wWECMO, veno-venous extracorporeal membrane oxygenation; vaECMO, veno-arterial extracorporeal membrane oxygenation; IVIG, intravenous immunoglobulin; Pip/ tazo, piperacillin/tazobactam. 
damage when patients had multiple risk factors, thereby leading to ARDS. According to World Health Organization guidelines, antiviral drug therapy can be beneficial when initiated early and at higher doses for longer durations [6]. Fatal cases of influenza usually feature secondary bacterial lung infections, so treatment with pneumococcal vaccination should be considered [7]. Our cases indicate that high Charlson co-morbidity index, sequential organ failure assessment score, and acute physiology and chronic health evaluation II score were associated with poor prognosis (Table 2). The late initiation of oseltamivir was also associated with poor response, even in a young patient (Fig. 3). The current cases support the observation that if a patient with many underlying medical conditions shows influenza symptoms, oseltamivir should be administered as soon as possible without waiting for the results of laboratory tests [8], and we should consider higher doses. Also routine screening for virologic markers is required [9].

In conclusion, influenza cannot be ruled out as a cause of severe lower respiratory tract infection. The cases described here indicate that influenza A (H3N2) viruses can cause ARDS associated with significant morbidity and mortality. When patients are suspected to have influenza, it is important to investigate relevant medical history and risk factors. If patients have numerous co-morbidities or risk factors, they should be observed carefully and started on aggressive management such as higher doses and longer duration as soon as possible regardless of the type of influenza infection. In the future, studies regarding specific risk factors associated with ARDS progression due to influenza A (H3N2) are warranted.

\section{REFERENCES}

1. Smith GJ, Bahl J, Vijaykrishna D, Zhang J, Poon LL, Chen H, et al. Dating the emergence of pandemic influenza viruses. Proc Natl Acad Sci U S A 2009;106:11709-12.

2. ANZIC Influenza Investigators, Webb SA, Pettila V, Seppelt I, Bellomo R, Bailey M, et al. Critical care services and 2009 H1N1 influenza in Australia and New Zealand. N Engl J Med 2009;361:1925-34.

3. Peris A, Zagli G, Bernardo P, Bonacchi M, Cozzolino M, Perretta L, et al. $\mathrm{H} 3 \mathrm{~N} 2$ virus as causative agent of ARDS requiring extracorporeal membrane oxygenation support. Case Rep Med 2014;2014:560208.

4. Oba Y, Salzman GA. Ventilation with lower tidal volumes as compared with traditional tidal volumes for acute lung injury. N Engl J Med 2000; 343:813.

5. Short KR, Kroeze EJ, Fouchier RA, Kuiken T. Pathogenesis of influenzainduced acute respiratory distress syndrome. Lancet Infect Dis 2014;14: 57-69.

6. Wang C, Armstrong SM, Sugiyama MG, Tabuchi A, Krauszman A, Kuebler WM, et al. Influenza-induced priming and leak of human lung microvascular endothelium upon exposure to Staphylococcus aureus. Am J Respir Cell Mol Biol 2015;53:459-70.

7. Centers for Disease Control and Prevention (CDC). Bacterial coinfections in lung tissue specimens from fatal cases of 2009 pandemic influenza A (H1N1) - United States, May-August 2009. MMWR Morb Mortal Wkly Rep 2009;58:1071-4.

8. Hui DS, Lee N, Chan PK. Clinical management of pandemic 2009 influenza A(H1N1) infection. Chest 2010;137:916-25.

9. Peris A, Bonizzoli M, Zagli G, Azzi A. Virological screening in cases of ALI/ARDS. J Hosp Infect 2012;82:300-1. 